\title{
Lecturers' Language Style and Higher Students' Academic Emotions In Indonesia
}

\author{
Fahmi Gunawan \\ Institut Agama Islam Negeri Kendari \\ Kendari, Indonesia
}

\author{
Abdul Kadir \\ Institut Agama Islam Negeri Kendari \\ Kendari, Indonesia
}

\begin{abstract}
This study aimed to examine the influence of lecturers' language style to the emotional state of students in Indonesia. This study originated from the emergence of emotional pressure felt by the students in the learning process which one of the factors comes from lecturers language style. This study utilized the qualitative and quantitative method. Participants were 30 students and ten lecturers. Furthermore, the findings showed that language style greatly affects the emotional condition of the student. That emotional aspect comprises shame, surprise, enjoyment, sadness, anxiety, anger, pride, and disappointment. Statistically, shame places the highest position with $86,67 \%$, followed by surprise $78.33 \%$, then enjoyment $70 \%$, sadness $68,89 \%$, anxiety $60 \%$, anger $58.89 \%$, pride $56.67 \%$, and disappointment $30 \%$. Finally, these findings become essential in psychology education due to it is in line with theory in which argued that academic, emotional condition could influence students' learning motivation and their interpersonal relationship to the lecturers.
\end{abstract}

Keywords-language style; academic emotions; higher education

\section{INTRODUCTION}

A person's rhetorical style or form of rhetoric shows the use of words in speech or writing. The style of the language can affect the emotion of the reader or the listener. The style of language deals with certain feelings of the heart. The sense of pleasure or sadness, as well as right or wrong impressions, will arise upon seeing or feeling certain conditions. The style of the bar function language convinces or affects the reader or listener. For example, local political conditions in Jakarta are growing due to the blasphemy case carried out by the Governor of DKI Jakarta in 2016. The style of language which says that Islamic scholars lie angered some groups. This anger triggers the emotions of society and leads to actions that threaten the security of the state. This phenomenon indicated that one's language styles could affect the psychological state of others.

Lecturers as educators are responsible for teaching or transferring knowledge to students. This achieving of a task well and efficiently if the lecturer can attract students' attention. In other words, the lecturer must be able to use the language style that is by the student's emotional habits and condition.

Research on the influence of lecturers' language style to academic emotions of higher students has been widely discussed by the scholars. The research on the university emotion of the students [1]-[8]. The study about anger in school learning [9]. The study about language as the perception of emotion [10]. Furthermore, the research about the association of emotion with language, knowledge, and academic outcome [11], [12]. Research about the relation of language and emotion to children reticence [13]. While the influence of the language of instruction to the academic selfconcept for Hongkong students [14]. The effect of emotion on learning and achievement on lexical decision performance [15].

Based on the previous studies, the research on language style of lecturers and its' influence on academic emotions of higher students in Indonesia was rarely conducted by the experts. For this purpose, the study was conducted.

\section{RESEARCH METHOD}

Descriptive mix method was conducted in this research. It was carried out by observing lecturer language style to students both in teaching and examining the final project and emotional condition of the students at Islamic State Institute of (IAIN) Kendari, Southeast Sulawesi, Indonesia.

Purposive sampling was utilized in the sample. Ten lecturers and 30 students were selected and observed. Collection data method by depth interviews and questionnaires were used in the research. Interviews and questionnaires were given to the students to identify academic emotion effect they received from the lecturers.

The academic emotion here refers to the emotion occurring in the process of learning as well as academic motivation or academic achievement [16], [17]. Nevertheless, the researchers did not utilize the model of the academic, emotional Questionnaire (AEQ) recommended by Pekrun and Govaerts [7], but the questionnaire based on the theory of Plutchik \& Kellerman that divides emotions into eight, namely shame, surprise, enjoyment, sadness, anxiety, anger, pride, and disappointment [18]. Then, the students' academic emotion was done statistically to find which the most dominant emotion was. Also, the language style producing the emergence of university emotion was also performed. To analyze the data, researchers utilized Keraf, Austin, and Plutchik theory. 


\section{RESULT AND DISCUSSION}

\section{A. Result}

The lecturers utilized various language styles when teaching and examining students' final project. However, overall, the lecturers only use two kinds of style, namely based on sentence structures and based on directness and indirectness of meaning. Austin argued that the speaker's utterance bring about of effects on the audience using uttering the sentences[19]. Lecturers' language style, for instance, had an impact on students' academic emotion, such as shame, surprise, enjoyment, sadness, anxiety, anger, pride, and disappointment. Thus, those emotional states influence students' self-motivation and their interpersonal relationship to the lecturers. As for the style of language affecting the emergence of the academic emotion is as follows:

- Please stand up in front of the class, since you did not do your assignment

- This paper did not deserve to be presented since it was like the paper of high school student

- Your assignment was signed as plagiarism from the website. Find out others

- I love the assignments you make today. I will add them tomorrow

- You are the next generation. Behave as an actual student

- The students should think ahead and have a great willingness to succeed in the future

Data (1-2) utilize the direct style. It was addressed to the students who did not perform the project and did the maximum in the learning process. Because of it, they were asked to stand in front of the class. The majority of students argued that they felt shame to stand. According to them, standing in front of the class is a social punishment. They were ashamed to be seen, assessed and considered to be lazy students. They felt that they had not self-esteem anymore. Consequently, one of the students argued that he be lazy to follow the course and would do remedial with other professors next semester.

Data (3-4) utilize the direct style of language as well. This style brought a sense of surprise and shocked for students themselves. The shock emerged when a professor asked them to find out other assignments due to being plagiarism. Plagiarism was against the law. Then, they were more shock as data (4) when they were asked to perform another assignment more than ever. Consequently, the majority of students argued that they are motivated to do the work even better and would prove to the professor that they could do their best. However, there were some students go down to the heavy load they burdened.

The style of language as data (5-6) is an indirect style. This language style makes students feel happy and proud. They were happy because they got motivation and direction to become successful students. Consequently, the students were delighted to the lecturers for motivating and lead them to have healthy interpersonal relationships to their lecturers.

Regarding the effect of language style of lecturers to the academic emotion of students, it can be seen that there were two kinds of response. The positive and negative response.

Figure 1 dam figure 2 describes the percentage of student response to the style language of lecturers.

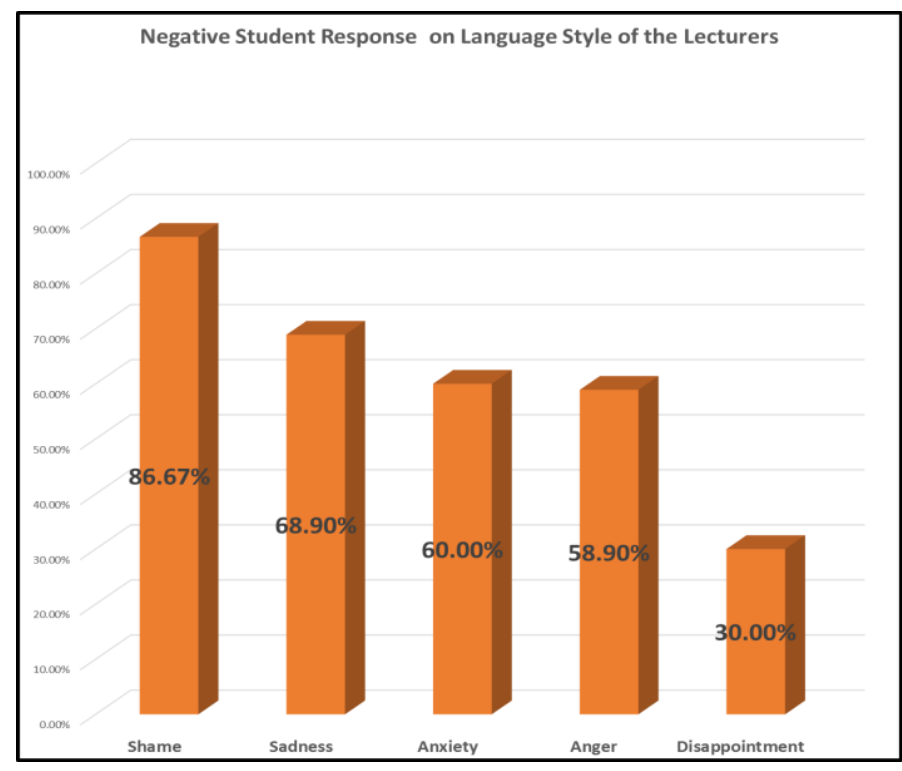

Fig. 1. Negative Students respond to language style of the lectures

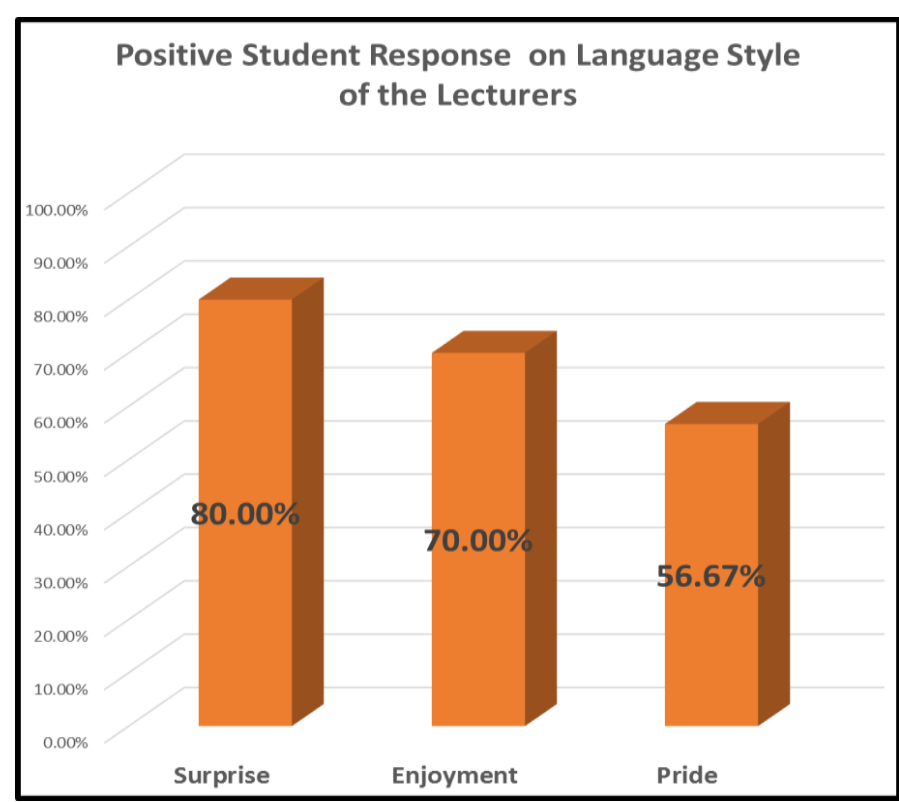

Fig. 2. Positive Students respond to language style of the lectures

Based on statistical data, it is found that students experience a for negative emotions in academic settings are varied. In figure 1 , it is shown that shame is the most dominant emotion with the highest percentage of $86.67 \%$. It was followed by sadness $68.89 \%$, anxiety $60 \%$, anger $58.89 \%$, and $30 \%$ disappointment. While the positive emotion showed that 
surprise is the most dominant emotion with the highest percentage of $80.00 \%$. It was followed by enjoyment $70.00 \%$ and pride $56.67 \%$.

\section{B. Discussion}

The results of the study indicated that the lecturers' language style effects on the appearance of students' academic emotions. The emergence of academic emotions of the students then influences their motivation in the learning process and their interpersonal relationships with lecturers. This study is in line with Pekrun, et al. in Germany and Govaerts \& Grégoire in France which stated that academic emotion affects students' thoughts, motivation, and action [7], [17]. Cognitive appraisal is the largest source of emotion. It may be shaped by social environment. Language style is regarded as one of the social settings.

However, the source of students' academic emotion is the main difference of this study with the previous survey. If the earlier studies tended to discuss academic emotion from a psychology perspectives, such as self-achievement, selfmotivation, and self-regulation, this study tends to discuss this matter from a linguistic standpoint. Similarly to other studies.

The research of Eisenberg et al. which focused on children language indicated that language greatly affects the emotional development of children, and these emotions also affect academic motivation and their language skills [11]. Instead, it is exciting to observe the research of Marsh at 7.802 students in Hong Kong, which argued that the language of instruction not affect academic self-concept and academic achievements of the students.

\section{CONCLUSION}

This study confirms that the style of language lecturers greatly affect the psychological condition of the students, especially the emotional aspects of academic. Meanwhile, the most dominant emotion is felt when listening to the language style lecturers was a feeling of shame, followed by a sense of surprise and pleasure. The existence of these emotions leads to increase or decrease the motivation of students in the learning process and improving and deteriorating interpersonal relationships students with the lecturers.

\section{References}

[1] R. Pekrun, T. Goetz, W. Titz, and R. P. Perry, 'Academic emotions in students' self-regulated learning and achievement: A program of qualitative and quantitative research', Educ. Psychol., vol. 37, no. 2, pp. 91-105, 2002.

[2] T. Goetz, A. C. Frenzel, R. Pekrun, N. C. Hall, and O. Lüdtke,
'Between-and within-domain relations of students' academic emotions.', J. Educ. Psychol., vol. 99, no. 4, p. 715, 2007.

[3] L. Linnenbrink-Garcia and R. Pekrun, 'Students' emotions and academic engagement: Introduction to the special issue', Contemp. Educ. Psychol., vol. 36, no. 1, pp. 1-3, 2011.

[4] A. C. Frenzel, T. M. Thrash, R. Pekrun, and T. Goetz, 'Achievement emotions in Germany and China a cross-cultural validation of the academic emotions questionnaire-mathematics', J. Cross. Cult. Psychol., vol. 38, no. 3, pp. 302-309, 2007.

[5] T. Goetz, A. C. Frenzel, N. C. Hall, and R. Pekrun, 'Antecedents of academic emotions: Testing the internal/external frame of reference model for academic enjoyment', Contemp. Educ. Psychol., vol. 33, no. 1, pp. 9-33, 2008.

[6] R. Pekrun, A. J. Elliot, and M. A. Maier, 'Achievement goals and achievement emotions: Testing a model of their joint relations with academic performance.', J. Educ. Psychol., vol. 101, no. 1, p. 115, 2009.

[7] R. Pekrun, T. Goetz, A. C. Frenzel, P. Barchfeld, and R. P. Perry, 'Measuring emotions in students' learning and performance: The Achievement Emotions Questionnaire (AEQ)', Contemp. Educ. Psychol., vol. 36, no. 1, pp. 36-48, 2011.

[8] T. Goetz, R. Pekrun, N. Hall, and L. Haag, 'Academic emotions from a social- cognitive perspective: Antecedents and domain specificity of students' affect in the context of Latin instruction', Br. J. Educ. Psychol., vol. 76, no. 2, pp. 289-308, 2006.

[9] M. Boekaerts, 'Anger in relation to school learning', Learn. Instr., vol. 3, no. 4, pp. 269-280, 1994.

[10] L. F. Barrett, K. A. Lindquist, and M. Gendron, 'Language as context for the perception of emotion', Trends Cogn. Sci., vol. 11, no. 8, pp. 327-332, 2007.

[11] N. Eisenberg, A. Sadovsky, and T. L. Spinrad, 'Associations of emotion- related regulation with language skills, emotion knowledge, and academic outcomes', New Dir. Child Adolesc. Dev., vol. 2005, no. 109, pp. 109-118, 2005.

[12] E. Sabara, H. A. Gani, D. Sidik, M. Mappalotteng, and G. D. Dirawan, 'Application of EDS-AV Scripts on Environmental Education in Increasing Attractivenessand Motivating Behavior Particularly Motoric Students Kindergarten', Int. J. Appl. Environ. Sci., vol. 11, no. 4, pp. 891-902, 2016.

[13] M. Fujiki, M. P. Spackman, B. Brinton, and A. Hall, 'The relationship of language and emotion regulation skills to reticence in children with specific language impairment', J. Speech, Lang. Hear. Res., vol. 47, no. 3, pp. 637-646, 2004.

[14] H. W. Marsh, K.-T. Hau, and C.-K. Kong, 'Multilevel causal ordering of academic self-concept and achievement: Influence of language of instruction (English compared with Chinese) for Hong Kong students', Am. Educ. Res. J., vol. 39, no. 3, pp. 727-763, 2002.

[15] K. M. Olafson and F. R. Ferraro, 'Effects of emotional state on lexical decision performance', Brain Cogn., vol. 45, no. 1, pp. 15-20, 2001.

[16] R. Pekrun, 'The impact of emotions on learning and achievement: Towards a theory of cognitive/motivational mediators', Appl. Psychol., vol. 41, no. 4, pp. 359-376, 1992.

[17] S. Govaerts and J. Grégoire, 'Development and construct validation of an academic emotions scale', Int. J. Test., vol. 8, no. 1, pp. 34-54, 2008.

[18] R. Plutchik and H. Kellerman, Emotion: theory, research and experience. Vol. 1, Theories of emotion. Academic Press, 1980.

[19] J. L. Austin, How to do things with words. Oxford university press, 1975. 